\title{
A comparative study of Fusobacterium necrophorum strains from human and animal sources by phenotypic reactions, pyrolysis mass spectrometry and SDS-PAGE
}

\author{
VAL HALL, B. I. DUERDEN, J. T. MAGEE*, H. C. RYLEY* and J. S. BRAZIER \\ PHLS Anaerobe Reference Unit and * Department of Medical Microbiology and Public Health Laboratory, \\ University of Wales College of Medicine, Cardiff CF4 4 XW
}

\begin{abstract}
Fusobacterium necrophorum strains from human infection (21) were compared with strains from animals (17 biotype $A, 2$ biotype $A B, 4$ biotype $B, 1$ biotype unknown), and the type strain NCTC 10575 in conventional tests reaction patterns (CTRPs), SDS-PAGE and pyrolysis mass spectrometry (PMS). Classifications from the three approaches showed one major consensus group comprising all human strains, and another comprising animal biotype A strains. Animal biotype B strains and one animal strain, designated with some doubt to biotype A, were outliers of the consensus 'human strain' group. Again, animal biotype AB strains were outliers of the consensus 'animal biotype A group', as was the type strain, which was clearly atypical in conventional tests and PMS. Colonial and microscopic characters showed good discrimination between the major consensus groups. However, only haemagglutination and the API-ZYM leucine arylamidase of the biochemical tests discriminated well between these groups. The 'animal biotype A group' clearly corresponds to $F$. necrophorum subsp. necrophorum, but synonymy of $F$. necrophorum subsp. funduliforme with the group of human strains was less certain. The latter subspecies was described solely on the basis of animal strains, all of biotype B, but each of four animal biotype B strains in this study was an outlier of the 'human strain group' in one or more of the characterisation approaches. Strains of $F$. necrophorum causing human infection were clearly distinct from the biotype A strains commonly found in animal infection. This has implications for the validity of animal models of human necrobacillosis. In view of these differences, it would be useful to have a validated designation for strains causing human infection. However, it would be premature to assume that the definition of $F$. necrophorum subsp. funduliforme encompasses the human strains in the absence of confirmatory DNAhomology and 16S rRNA-sequencing studies.
\end{abstract}

\section{Introduction}

Fusobacterium necrophorum is a recognised pathogen important in medical and veterinary microbiology. Most gram-negative anaerobes are opportunists found in polymicrobial infections, but $F$. necrophorum is a primary pathogen causing specifically recognisable, serious disease in man and animals. These diseases are varied, but described collectively as 'necrobacillosis' [1] with the covert implication that the diseases in man and animals are similar and caused by the same organism. However, there is increasing evidence that

Received 20 Dec. 1996; accepted 28 March 1997. Corresponding author: Ms V. Hall. these diseases, and the organisms causing them, are distinct.

F. necrophorum is an obligately anaerobic, non-motile, gram-negative bacillus with highly variable morphology. Animal strains usually show long filamentous cells; human strains tend to show much shorter, pleomorphic morphology and may be predominantly coccobacillary. Strains are generally $\beta$-haemolytic on sheep, human and horse blood agar, produce $n$-butyric acid but not iso-butyric or iso-valeric acids, and have a DNA content of $c .30 \mathrm{~mol} \%(\mathrm{G}+\mathrm{C})$ [2]. $\quad F$. necrophorum is distinguished from other fusobacteria by lipase and indole production, and conversion of lactate and threonine to propionate [3]. It is inhibited by bile and bile salts but tolerant of various dyes and 
susceptible to penicillin and high potency kanamycin disks (1 mg), but resistant to rifampicin [4]. Cell adhesion, which may be important in establishing infection, has been demonstrated in tissue-culture cells and by haemagglutination; these properties are expressed most strongly by animal isolates $[5,6]$.

Loeffler first described the organism from calves with a necrotising throat infection which he called 'calf diphtheria' [7]. Further papers linked this organism with an outbreak of labial necrosis in laboratory rabbits [8], liver abscesses in cattle [9] and genital ulceration and sepsis in man [10]. The classical report of infection in man [11] describes a syndrome 'so characteristic that mistake is almost impossible ... it becomes relatively easy to make a diagnosis on clinical findings', but clinicians still frequently fail to make a rapid diagnosis [12]. Human necrobacillosis usually occurs in healthy young adults and there are no known predisposing factors. It presents as an acute sore throat with purulent exudate, pseudomembrane over the tonsils, a high fever and rigors. Lymphadenopathy in submandibular and cervical nodes, and metastatic abscesses in the liver, kidney and particularly the lungs, occur. Pyogenic arthritis and osteomyelitis are common $[1,11,12]$. Before the antibiotic era, mortality was high; however, with antibiotic treatment, response is generally rapid and recovery complete. The antibiotics of choice are penicillin and metronidazole, but many empirical regimens can be successful, provided they are not based on aminoglycosides.

Foot rot is a major infective problem of cattle, sheep, goats, pigs and deer that causes widespread economic losses. Unlike other forms of necrobacillosis, this is a localised, polymicrobial infection more akin to other anaerobic infections. It is common in animals housed and pastured on wet ground and under stress, causing bacterial dermatitis with superficial necrosis of the interdigital skin, spreading rapidly to the dermis and hoof margin. There is a foul, purulent discharge and the hoof may separate. $F$. necrophorum is implicated in most forms of foot rot but usually with other putative pathogens such as Dichelobacter (Bacteroides) nodosus $[1,13]$. Other animal diseases associated with $F$. necrophorum are: necrotising throat infection with multiple tonsillar abscesses and suppuration of the associated lymph nodes; and multiple hepatic abscesses in cattle, where mucosal damage leads to rumenitis, and organisms enter the liver via the portal venous system. Further types of necrotic abscesses that cause widespread tissue destruction and death include labial necrosis in laboratory rabbits and lumpy jaw necrobacillosis in wallabies [14].

The differences between human and animal infections raised doubts that the diseases and causative organisms were the same. Fiévez [15] confirmed differences between strains from different sources and divided strains into three biotypes, $\mathrm{A}, \mathrm{B}$ and $\mathrm{C}$, with an intermediate group between $\mathrm{A}$ and $\mathrm{B}(\mathrm{AB})$. The nonhaemolytic biotype $\mathrm{C}$ is now considered to be a separate species, F. pseudonecrophorum [16]. The two biotypes of $F$. necrophorum were best distinguished by pathogenicity tests in mice and agglutination tests with chick erythrocytes. Biotype A strains were virulent, gave strong haemagglutination and were generally from diseased animals, whereas biotype B strains were from animal intestinal flora or from infections in man and tended to be more pleomorphic [17]. Smith and Thornton [18] found a clear gradation in virulence in a mouse subcutaneous abscess model: animal biotype A strains were most virulent; animal biotype B and most human strains were less virulent in pure and mixed infections. They suggested that 'the term necrobacillosis, as used by medical and veterinary microbiologists, refers to diseases that differ in important respects' [18].

Shinjo et al. [19-21] proposed two subspecies, $F$. necrophorum subsp. necrophorum (biotype A) and $F$. necrophorum subsp. funduliforme (biotype $\mathrm{B}$ ), on the basis of clear biochemical, morphological and DNAhomology differences between strains of biotype A and B. Small-subunit rRNA sequencing supported the subspecies division, placing a biotype $A B$ strain with biotype B strains [22]. However, the strains studied were of animal origin.

A collaborative study involving members of the Society for Anaerobic Microbiology and co-ordinated by the PHLS Anaerobe Reference Unit (ARU) was established to compare human with animal-derived strains. This report outlines the results from conventional metabolic and whole-cell composition studies obtained at the ARU. Reports of parallel studies in the collaborating laboratories are also published in this issue $[23,24]$.

\section{Materials and methods}

\section{Bacterial strains}

Fifty blind-coded (F1-50) freeze-dried F necrophorum cultures were distributed to participating centres. These comprised the type strain (NCTC 10575), 21 human clinical strains (all of unknown biotype), nine bovine strains (four biotype A, two biotype AB, two biotype B and one biotype unknown), nine strains from wallabies (seven biotype A and two biotype B) and six strains from other animals (all biotype A). The animal strains were provided by Dr G. R. Smith, The Institute of Zoology, London; the human isolates were collected by the ARU. Four cultures were replicates of: the type strain; one biotype A strain from an antelope; one biotype $\mathrm{B}$ wallaby strain; and one human strain. The blind code was broken upon completion of participants' analyses. The sources and original designations of the 46 strains are shown in Table 1. 
Table 1. Sources and designations of isolates

\begin{tabular}{|c|c|c|c|c|}
\hline Code (F) no. & Source & Site of isolation & Biotype* & Original designation \\
\hline 1 & Bovine & Liver & B & Berg B2035 \\
\hline 2 & Human & $\mathrm{BC}$ & NK & C289/93 \\
\hline 3,49 & Antelope & Head & A & A4 \\
\hline 4 & Human & $\mathrm{BC}$ & NK & $\mathrm{C} 700 / 92$ \\
\hline 5 & Axis deer & Faeces & A & A146 \\
\hline 6 & Human & $\mathrm{BC}$ & NK & $0669 / 91$ \\
\hline 7 & Ox & CNS & A & A148 (large) \\
\hline 8 & $\mathrm{Ox}$ & CNS & A & A148 (small) \\
\hline 9 & Human & $\mathrm{BC}$ & NK & $\mathrm{C} 775 / 92$ \\
\hline 10,32 & Bovine & Liver & A & NCTC 10575 \\
\hline 11 & Wallaby & Head & A & A117 \\
\hline 12 & Human & $\mathrm{BC}$ & NK & $54269 / 91$ \\
\hline 13 & Human & $\mathrm{BC}$ & NK & $6834 / 91$ \\
\hline 14 & Kudu & Faeces & A & A156 \\
\hline 15 & Human & Bronchus & NK & $\mathrm{C} 817 / 92$ \\
\hline 16 & Bovine & Liver & $A B$ & Berg AB2030R \\
\hline 17,40 & Human & $\mathrm{BC}$ & NK & $\mathrm{C} 202 / 93$ \\
\hline 18 & Human & $\mathrm{BC}$ & NK & $\mathrm{C} 1070 / 92$ \\
\hline 19,23 & Wallaby & Spleen & B & A19 \\
\hline 20 & Bovine & Rumen & A & A149 \\
\hline 21 & Human & $\mathrm{BC}$ & NK & C247/93 \\
\hline 22 & Human & $\mathrm{BC}$ & NK & $\mathrm{C} 412 / 92$ \\
\hline 24 & Wallaby & Jaw & A & Al0 \\
\hline 25 & Wallaby & Jaw & A & A102 \\
\hline 26 & Human & $\mathrm{BC}$ & NK & C1153/92 \\
\hline 27 & Human & $\mathrm{BC}$ & NK & C195/93 \\
\hline 28 & Wallaby & Stomach & A & A159 \\
\hline 29 & Human & $\mathrm{BC}$ & NK & $12854 / 91$ \\
\hline 30 & Bovine & Liver & B & Berg B2079 \\
\hline 31 & Oryx & Faeces & A & A157 \\
\hline 33 & Wallaby & Stomach & A & A47 \\
\hline 34 & Mara & Abscess & A & A53 \\
\hline 35 & Human & $\mathrm{BC}$ & NK & $\mathrm{C} 13 / 93$ \\
\hline 36 & Bovine & Litter & NK & L7 \\
\hline 37 & Human & Ear & NK & $36114 / 91$ \\
\hline 38 & Wallaby & Face & A & A42 \\
\hline 39 & Bovine & Faeces & A & F2 \\
\hline 41 & Peccary & Abscess & A & Al \\
\hline 42 & Human & $\mathrm{BC}$ & NK & $18911 / 91$ \\
\hline 43 & Wallaby & Foot & B & A62 \\
\hline 44 & Human & $\mathrm{BC}$ & NK & $\mathrm{C} 1217 / 92$ \\
\hline 45 & Wallaby & NK & A & A89 \\
\hline 46 & Bovine & Liver & $A B$ & Berg AB2030S \\
\hline 47 & Human & $\mathrm{BC}$ & NK & $28619 / 91$ \\
\hline 48 & Human & $\mathrm{BC}$ & NK & C1178/92 \\
\hline 50 & Human & $\mathrm{BC}$ & NK & $91723 / 90$ \\
\hline
\end{tabular}

BC, blood culture; CNS, central nervous system; NK, not known.

${ }^{*}$ Biotype designations were kindly supplied by Dr G. R. Smith, Institute of Zoology, London. NK, biovar unknown

\section{Conventional tests}

Coded cultures were reconstituted in Brain Heart Infusion Broth (Oxoid), cultured on Fastidious Anaerobe Agar (LabM) with horse blood 7\% v/v (FAA) and incubated anaerobically at $37^{\circ} \mathrm{C}$ for $48 \mathrm{~h}$. Unless otherwise stated, tests were performed from $48-\mathrm{h}$ cultures on FAA. Colony texture, shape, size, $\beta$ haemolysis, fluorescence under long-wave UV illumination [25], disk susceptibility to metronidazole $(5 \mu \mathrm{g})$, lecithinase or lipase production on egg-yolk medium, and microscopic morphology were recorded. A spot indole test was performed as described by Lombard and Dowell [26], except that colonies grown on FAA were inoculated directly on to reagent-soaked filter paper. Production of acid from fructose, glucose, lactose, mannose and sucrose, and hydrolysis of aesculin, gelatin and starch were detected by the methods described elsewhere [27-29]. Tests for preformed enzymes were performed in the API-ZYM system (bioMérieux) with inocula prepared in sterile distilled water to McFarland's standard 5-6 and reactions were recorded after incubation at $37^{\circ} \mathrm{C}$ for $4 \mathrm{~h}$.

\section{Chick erythrocyte haemagglutination}

Colonies were emulsified in $0.5 \mathrm{ml}$ of saline to McFarland's standard 6, washed twice in saline, centrifuged at $400 \mathrm{~g}$ for $15 \mathrm{~min}$, and resuspended in saline. Chick erythrocytes were washed four times as above and a suspension $1-2 \% \mathrm{v} / \mathrm{v}$ in saline was prepared. Loopfuls of bacterial cell suspension and erythrocytes were mixed briefly on a glass slide and observed for haemagglutination. 


\section{Gas-liquid chromatography of end-products of metabolism}

Extracts from 48-h cultures in Fastidious Anaerobe Broth (LabM) with cooked meat granules were prepared as described elsewhere [30] for analysis of total volatile fatty acid profile and conversion of lactate to propionate. Assay for threonine conversion to propionate was performed by comparison of propionate peaks obtained from agar plugs of cultures on FAA with and without threonine $0.3 \% \mathrm{w} / \mathrm{v}$.

\section{Pyrolysis mass spectrometry}

Pyrolysis was performed on 48-h FAA cultures and the mass spectra were analysed as described elsewhere [31].

\section{Numerical taxonomy}

The following characters were coded 0 , negative or 1 , positive: colonial characters-cream, grey, opaque, smooth surface, umbonate, raised, edge entire; presence in microscopy of-coccobacillary forms, short straight bacilli, long straight bacilli, and long curved or convoluted bacilli; spot indole; and acid from glucose and fructose. Colony diameter was coded $0(<1 \mathrm{~mm})$, $1 \quad(1-1.9 \mathrm{~mm}), 2 \quad(2-2.9 \mathrm{~mm}), 3 \quad(3-3.9 \mathrm{~mm}), 4$ $(>4 \mathrm{~mm})$. API-ZYM tests, haemagglutination and conversion of lactate to propionate were coded 0 (negative), 1 (weak), 2 (positive). Results were analysed in the Clustan II-PC programme suite, with the Euclidian distance coefficient as a similarity measure in the UPGMA hierarchical agglomeration strategy.

\section{SDS-PAGE}

The protein content of a dense saline suspension of each strain was estimated in the Coomassie Blue dyebinding assay [32] and adjusted to $400 \mu \mathrm{g} / \mathrm{ml}$. Four parts of this suspension and one part of SDS lysing solution were mixed and held at $100^{\circ} \mathrm{C}$ for $4 \mathrm{~min}$. Suspensions were stored at $-20^{\circ} \mathrm{C}$ and reheated at $100^{\circ} \mathrm{C}$ for $2 \mathrm{~min}$ before use. Electrophoresis was performed on 20- $\mu 1$ volumes of suspension separating in $14 \times 16-\mathrm{cm}$ polyacrylamide $10 \% \mathrm{w} / \mathrm{v}$ vertical slab gels in a discontinuous SDS buffer system [33]. Initial voltage was $100 \mathrm{~V}$ for $30 \mathrm{~min}$ followed by $300 \mathrm{~V}$ for $5 \mathrm{~h}$. Gels were stained by a one-step Coomassie Blue staining method adapted from that of Chen et al. [34].

\section{Results}

\section{Conventional tests}

All strains were $\beta$-haemolytic, fluoresced bright yellowgreen under UV illumination and were susceptible to metronidazole ( $5 \mu \mathrm{g}$ disk). Colonies of 25 cultures (one duplicate) were cream, opaque, smooth, umbonate/ raised, entire edged and of diameter $1.3-2.5 \mathrm{~mm}$; in 17 cultures (one duplicate), colonies were grey, semiopaque, mottled, umbonate, erose edged and of diameter $3.0-4.2 \mathrm{~mm}$; and the remaining eight cultures (including NCTC 10575; two duplicates) showed intermediate morphologies. The group with smaller cream colonies comprised all of the human strains, three animal biotype B strains and one atypical animal biotype A strain (culture code F41). The group with larger grey colonies comprised 15 (one duplicate) animal (biotype A), one animal (biotype $\mathrm{AB}$ ) and one animal (biotype unknown) strains.

Microscopically, all strains stained as gram-negative bacilli. Two major morphological groups were observed which correlated with the major colonial types. Strains of the 'small cream' colony group were highly pleomorphic with coccobacillary and long curved to convoluted cells. Strains of the 'large grey' colony group were moderately pleomorphic with short and long, straight or slightly curved rods. The "miscellaneous' group showed more uniform morphology with short straight rods predominating.

In conventional tests all cultures gave positive reactions for indole, lipase on egg-yolk agar and gelatin hydrolysis; all cultures gave negative reactions for lecithinase, starch hydrolysis, aesculin hydrolysis, and fermentation of lactose, mannose and sucrose. In API-ZYM all cultures gave positive reactions for lipase esterase, esterase, acid phosphatase and naphthol-AS-BI-phosphohydrolase; all cultures gave negative reactions for valine arylamidase, cystine arylamidase, trypsin, chymotrypsin, $\alpha$ - and $\beta$-galactosidase, $\beta$-glucuronidase, $\alpha$ - and $\beta$-glucosidase, $N$ acetyl $\beta$-glucosaminidase, $\alpha$-mannosidase and $\alpha$-fucosidase. Results of other biochemical tests are shown in Table 2.

In the haemagglutination test (Table 2), 19 strains, plus two duplicates (comprising 15 animal biotype A, two animal biotype $A B$, one animal biotype unknown and NCTC 10575) agglutinated the erythrocytes. One animal biotype B strain and its duplicate showed weak haemagglutination. Twenty-six strains, plus one duplicate, comprising 21 human, three animal biotype B and two animal biotype A strains did not agglutinate the erythrocytes.

All strains produced major amounts of acetic and $n$ butyric acids, converted threonine to propionate, and were negative for production of iso-butyric, iso- and $n$-valeric, and iso- and $n$-caproic acids. Twenty-seven strains produced major amounts of propionic acid from lactate, 18 strains converted minor amounts, and one strain did not convert lactate to propionate, possibly due to poor growth. The amounts of propionic acid produced varied between duplicate strains and showed no correlation with biotype or source. Results of these and other biochemical tests 
Table 2. Results of biochemical tests

\begin{tabular}{|c|c|c|c|c|c|}
\hline \multirow[b]{3}{*}{ Test } & \multicolumn{5}{|c|}{ Number of strains positive } \\
\hline & \multirow{2}{*}{$\frac{\text { NCTC } 10575}{A^{*}(n=1)}$} & \multicolumn{3}{|c|}{ From animals } & \multirow{2}{*}{$\frac{\text { From man }}{\mathrm{NK}(\mathrm{n}=21)}$} \\
\hline & & $A \dagger(n=16)$ & $\mathrm{AB}(\mathrm{n}=2)$ & $B(n=4)$ & \\
\hline Fructose & 1 & 12 & 2 & 4 & 21 \\
\hline Glucose & 1 & 15 & 2 & 4 & 20 \\
\hline Alkaline phosphatase & 1 & 16 & 2 & 4 & 20 \\
\hline API-ZYM lipase & 1 & 16 & 2 & 1 & 9 \\
\hline Leucine arylamidase & 1 & 12 & 0 & 0 & 0 \\
\hline Haemagglutination & 1 & 16 & 2 & 1 & 0 \\
\hline Lactate $\rightarrow$ propionate (major) & 1 & 11 & 1 & 2 & 11 \\
\hline Lactate $\rightarrow$ propionate (trace) & 0 & 4 & 1 & 2 & 10 \\
\hline
\end{tabular}

* The biotypes were: A, B, AB (intermediate) or NK (not known).

†Excluding atypical strains 14 and 41 of biotype A, but including strain F36 of unknown biotype.

are shown in Table 2 , and the classification results for all approaches are detailed in Table 3.

\section{Classification based on conventional test results}

This divided the strains into two main clusters, I and II, each with a small number of outliers (Table 3). Code breaking revealed that cluster I contained all of the human strains of unknown biotype, the four animal biotype $B$ strains and the morphologically atypical biotype A animal strain (culture code F41). One animal biotype $\mathrm{B}$, and one human strain were outliers of cluster I, as were three further animal biotype A strains, in subclusters $\mathrm{Ib}-\mathrm{Ie}$. Cluster IIa contained 13 of the 17 animal biotype A strains, one animal biotype $\mathrm{AB}$ strain and one animal strain (F36) of unknown biotype. The NCTC reference strain (biotype A) and its duplicate were outliers in cluster $\mathrm{IIb}$, and one animal biotype $\mathrm{AB}$ strain formed cluster IIc. All duplicate cultures clustered in agreement.

\section{Pyrolysis mass spectrometry}

PMS showed a greater diversity in overall composition than was apparent in conventional tests. It again distinguished clearly between two main groups, but

Table 3. Details of source and group membership* of strains

\begin{tabular}{|c|c|c|c|c|c|c|c|}
\hline \multirow[b]{2}{*}{ Designation $\dagger$} & \multirow{2}{*}{$\begin{array}{c}\text { Number of } \\
\text { strains }\end{array}$} & \multirow[b]{2}{*}{ Source } & \multicolumn{5}{|c|}{ Group in } \\
\hline & & & Consensus & Biotype & CTRPs & PMS & SDS \\
\hline $9,17(40), 48$ & 3 & Human & $\mathrm{H}$ & NK & Ia & 1 & $\mathrm{i}$ \\
\hline 2,47 & 2 & Human & $\mathrm{H}$ & NK & Ia & 1 & ii \\
\hline 15 & 1 & Human & $\mathrm{H}$ & NK & Ic & 1 & $\mathrm{ji}$ \\
\hline $4,18,44$ & 3 & Human & $\mathrm{H}$ & NK & Ia & 1 & iv \\
\hline 27 & 1 & Human & $\mathrm{H}$ & NK & Ia & 2 & $\mathrm{ii}$ \\
\hline $6,21,22,26,29,37$ & 6 & Human & $\mathrm{H}$ & NK & Ia & 2 & iv \\
\hline 35 & 1 & Human & $\mathrm{H}$ & NK & Ia & 2 & $\mathbf{v}$ \\
\hline $12,13,42,50$ & 4 & Human & $\mathrm{H}$ & NK & Ia & 2 & iii \\
\hline $19(23)$ & 1 & Animal & $\mathrm{H}(\mathrm{O})$ & B & Ib & 1 & vi \\
\hline 43 & 1 & Animal & $\mathrm{H}(\mathrm{O})$ & B & Ia & 1 & vi \\
\hline 1,30 & 2 & Animal & $\mathrm{H}(\mathrm{O})$ & B & Ia & 3 & iv \\
\hline 41 & 1 & Animal & $\mathrm{H}(\mathrm{O})$ & A? & Ia & 3 & iv \\
\hline 34 & 1 & Animal & $\mathrm{A}$ & A & Ib & 4 & $\mathrm{v}$ \\
\hline 20,31 & 2 & Animal & A & A & IIa & 8 & iv \\
\hline $5,28,38,45$ & 4 & Animal & A & A & IIa & 8 & $\mathrm{v}$ \\
\hline $3(49), 39$ & 2 & Animal & A & A & IIa & 6 & $\mathbf{v}$ \\
\hline 11,24 & 2 & Animal & A & A & IIa & 5 & $\mathrm{v}$ \\
\hline 25 & 1 & Animal & A & $\mathrm{A}$ & IIa & 4 & $\mathrm{v}$ \\
\hline 36 & 1 & Animal & $A$ & NK & IIa & 4 & $\mathrm{v}$ \\
\hline 33 & 1 & Animal & A & A & IIa & 7 & $\mathrm{v}$ \\
\hline 7 & 1 & Animal $\ddagger$ & A & A & Ila & 8 & $\mathrm{v}$ \\
\hline 8 & 1 & Animal $\ddagger$ & A & A & Id & 8 & $\mathrm{v}$ \\
\hline 14 & 1 & Animal & $\mathrm{A}(\mathrm{O})$ & A & Ie & 9 & vi \\
\hline 16 & 1 & Animal & $\mathrm{A}(\mathrm{O})$ & $\mathbf{A B}$ & IIa & 10 & $\mathrm{v}$ \\
\hline 46 & 1 & Animal & $A(O)$ & $\mathbf{A B}$ & IIc & 11 & $\mathrm{v}$ \\
\hline $10(32)$ & 1 & NCTC 10575 & $A(O)$ & $\mathrm{A}$ & IIb & 12 & $\mathrm{v}$ \\
\hline
\end{tabular}

CTRPs, conventional test reaction patterns; PMS, pyrolysis mass spectrometry; SDS, SDS-PAGE. Consensus groups are designated: H, human or $A$, animal with $(\mathrm{O})$ suffixed if the isolate was clearly an atypical outlier of the consensus group.

* Bold type indicates group membership atypical of the consensus designation.

$\dagger$ Blind-coded $(F)$ number in study with bracketed numbers indicating duplicate cultures.

\$Large and small colonial variants of same isolate. 
there was greater diversity within groups, especially amongst the animal strains. All duplicate cultures clustered in agreement. PMS groups 1,2 and, possibly, 3 and 4 formed a super-cluster containing all human strains (groups 1 and 2), all animal biotype B strains and culture 41 (groups 1 and 3) and three animal biotype A strains (group 4). Groups 5-9 contained the remainder of the animal biotype A strains, groups 10 and 11 contained the animal biotype $A B$ strains; the NCTC reference strain (biotype A) was an extreme outlier in group 12. The distance structure based on PMS was complex and could be only poorly visualised in dendrograms and ordination diagrams.

\section{SDS-PAGE of whole-cell protein extracts}

Analysis was difficult because of the complex banding patterns obtained. Strains were divided into 19 distinct groups comprising 1-10 strains based on differences in molecular size of the major protein bands. These groups were tentatively assessed to form six clusters. Human strains predominated in clusters i, ii and iii, animal biotype $\mathrm{B}$ strains in cluster vi, and animal biotype $A$ strains in cluster v. Biotype $A B$ strains and the type strain were also found in cluster v. Duplicate cultures of the animal biotype A and B strains and the NCTC strain clustered in agreement. The duplicates of the human strain were found in clusters $i$ and iv.

\section{Discussion}

Overall (Table 1), the classification obtained from these diverse approaches showed remarkable agreement, giving a clear consensus division of the strains into two major groups, one containing all of the human strains, and the other the majority of the animal biotype A strains. For the 37 strains in these groups, the classification results concurred for all, or all but one, of the characterisation approaches. However, for nine strains the situation was more complex. The animal biotype $\mathrm{B}$ strains and the atypical biotype A strain F41 tended to cluster as outliers, usually of the 'human strain' group, in the various classifications. Again, the animal biotype $\mathrm{AB}$ strains and biotype $\mathrm{A}$ strain 14 tended to cluster as outliers of the 'animal strain' group. The clustering of strain F41 with biotype B strains in various tests casts doubt on its original biotype designation. Tests, including pathogenicity studies, indicate that it may be of biotype $B$. The type strain (NCTC 10575), originally a bovine biotype A strain, was clearly atypical, forming a single member cluster outlying the 'animal group' in CTRPs and PMS.

The results clearly indicate that $F$ necrophorum is a heterogeneous species, forming at least two groups distinct in morphology, biochemistry, whole-cell composition, protein composition and, probably, host range, supporting the subspeciation of $F$. necrophorum suggested by Shinjo et al. [20,21]. There is little doubt that the consensus 'animal group' corresponds to $F$. necrophorum subsp. necrophorum. However, the consensus 'human group' may not be synonymous with $F$. necrophorum subsp. funduliforme. The latter subspecies was described for animal biotype B strains and all of the four such strains included in this study were outliers of the 'human group' in at least one characterisation approach - two in PMS (strains F1 and F30), one in SDS-PAGE (F43) and one in CTRPs and SDS-PAGE (F19). Conversely, the morphological description of subsp. funduliforme [20, 24] fits well with that of the 'small cream colony' group that was essentially equivalent to the consensus 'human group', as does the lack of haemagglutinating activity in this group. However, medical microbiologists should be cautious in adopting this subspecies designation in view of the lack of DNA hybridisation and 16S rRNA sequence evidence for synonymy between human and animal biotype $\mathrm{B}$ strains.

Of the non-morphological conventional tests, only leucine arylamidase and haemagglutination reliably distinguished between the consensus animal and human groups. Both lipase and phosphatase tests, in the various formats investigated here (egg-yolk agar; API-ZYM lipase and API-ZYM lipase esterase; APIZYM alkaline phosphatase and API-ZYM acid phosphatase), failed to differentiate the groups reliably. This contrasts with the results of Amoako et al. [21], probably due to differences in methodology.

The human strains were considered to be highly pathogenic to their human hosts and may, as judged by our results, be of biotype $B$, which has been shown to be of low virulence in several animal species [19, 35-37] in single or mixed infections. None of the human strains appeared to be of biotype A, which is highly virulent in many animal species. Our findings clearly support the observation of Smith and Thornton [18] that 'the term necrobacillosis, as used by medical and veterinary microbiologists, refers to diseases that differ in important respects'. This has implications for the use of animal models in studies of pathogenicity for man.

Further study by molecular methods, particularly DNA-DNA hybridisation and 16S rRNA sequencing, with a view to establishing the relationship between human strains and $F$. necrophorum subsp. funduliforme is required. We emphasise the atypical nature of the type strain as a warning to other workers. The collection of strains has been preserved, and we would be pleased to assist other groups who may wish to progress this work.

We are grateful to Dr G. R. Smith (Institute of Zoology, London) for providing strains from animal sources and to P. Talbot (ARU) for technical assistance. 


\section{References}

1. Alston JM. Necrobacillosis in Great Britain. BMJ 1955; 2: 1524-1528.

2. Moore WEC, Holdeman LV, Kelly RW. Fusobacteria. In: Krieg NR, Holt JG (eds) Bergey's Manual of systematic bacteriology, vol 1. Baltimore, Williams \& Wilkins. 1984: 631-637.

3. Summanen P, Baron EJ, Citron DM, Strong CA, Wexler HM, Finegold SM. Wadsworth Anaerobic bacteriology manual, 5th edn. Belmont, CA, Star Publishing Company. 1993.

4. Duerden BI. The Bacteroidaceae: Bacteroides, Fusobacterium and Leptotrichia. In: Parker MT, Collier LH (eds) Topley and Wilson's Principles of bacteriology, virology and immunity, 8th edn, vol 2. London, Edward Arnold. 1990: 551-575.

5. Shinjo T, Miyazato X, Kiyoyama H. Adherence of Fusobacterium necrophorum biovar A and B to erythrocytes and tissue culture cells. Ann Inst Pasteur Microbiol 1988; 139: 453-460.

6. Kanoe M, Yamanaka M. Bovine platelet aggregation by Fusobacterium necrophorum. J Med Microbiol 1989; 29: 1317.

7. Loeffler F. Untersuchungen über die Bedentung der Mikroorganismen für die Entstehung der Diphtherie beim menschen, bei der Taube und beim kalbe. Mitt K Gesundheitsamte 1884; 2: $421-429$.

8. Altman P, Schmorl G. Ueber ein pathogenes Fadenbacterium (Streptothrix cuniculi). Deutsche Zeitschrift für Thiermedizin, Leipzig 1890-1; 17: 375-408.

9. Bang BLF. Die Aetiologie des seuchenhaften ("infectiösen") Verwerfens. Zeitschrift für Thiermedizin 1897; 1: 241-278.

10. Hallé J. Recherches nur la bacteriologie du canal génital de la femme. Thèse de Paris 1898.

11. Lemierre A. On certain septicaemias due to anaerobic organisms. Lancet 1936; 1: 701-703.

12. Moore-Gillon J, Lee TH, Eykyn SJ, Phillips I. Necrobacillosis: a forgotten disease. $B M J$ 1984; 288: 1526-1527.

13. Langworth BF. Fusobacterium necrophorum: its characteristics and role as an animal pathogen. Bacteriol Rev 1977; 41: 373390.

14. Ashton DG. In: The scientific report of the Zoological Society of London 1979-1981. J Zool Lond 1982; 197: 91-92.

15. Fievez L. Étude comparée des souches de Sphaerophorus necrophorus isolates chez l'homme et chez l'animal. Brussels: Presses Académiques Européennes. 1963.

16. Shinjo T, Hiraiwa K, Miyazato S. Recognition of biovar $\mathrm{C}$ of Fusobacterium necrophorum (Flugge) Moore and Holdeman as Fusobacterium pseudonecrophorum sp. nov., nom. rev. (ex Prevot 1940). Int $J$ Syst Bacteriol 1990; 40: 71-73.

17. Dack GM, Dragstedt LR, Heinz TE. Further studies on Bacterium necrophorum isolated from cases of chronic ulcerative colitis. J Infect Dis 1937; 60: 335-355.

18. Smith GR, Thornton EA. Pathogenicity of Fusobacterium necrophorum strains from man and animals. Epidemiol Infect 1993; 110: 499-506.

19. Shinjo T, Miyazato S, Kaneuchii C, Mitsuoka T. Physiological and biochemical characteristics of Fusobacterium necrophorum biovar A and biovar B strains and their deoxyribonucleic acid homology. Nippon Juigaku Zasshi 1981; 43: 233-241.
20. Shinjo T, Fujisawa T, Mitsuoka T. Proposal of two subspecies of Fusobacterium necrophorum (Flügge) Moore and Holdeman: Fusobacterium necrophorum subsp. necrophorum subsp. nov., nom. rev. (ex Halle 1898), and Fusobacterium necrophorum subsp. funduliforme subsp. nov., nom. rev. (ex Flügge 1886). Int J Syst Bacteriol 1991; 41: 395-397.

21. Amoako KK, Goto Y, Shinjo T. Comparison of extracellular enzymes of Fusobacterium necrophorum subsp. necrophorum and Fusobacterium necrophorum subsp. funduliforme. $J$ Clin Microbiol 1993; 31: 2244-2247.

22. Nicholson LA, Morrow CJ, Corner LA, Hodgson ALM Phylogenetic relationship of Fusobacterium necrophorum A, $\mathrm{AB}$, and $\mathrm{B}$ biotypes based upon $16 \mathrm{~S}$ rRNA gene sequence analysis. Int $J$ Syst Bacteriol 1994; 44: 315-319.

23. Brown R, Lough HG, Poxton IR. Phenotypic characteristics and lipopolysaccharides of human and animal isolates of Fusobacterium necrophorum. J Med Microbiol 1997; 46: 873-878.

24. Smith GR, Thornton EA. Classification of human and animal strains of Fusobacterium necrophorum by their pathogenic effects in mice. J Med Microbiol 1997; 46: 879-882.

25. Brazier JS. Yellow fluorescence of fusobacteria. Lett Appl Microbiol 1986; 2: 125-126.

26. Lombard GL, Dowell VR. Comparison of three reagents for detecting indole production by anaerobic bacteria in microtest systems. J Clin Microbiol 1983; 18: 609-613.

27. Phillips KD. A simple and sensitive technique for determining the fermentation reactions of non-sporing anaerobes. $J$ Appl Bacteriol 1976; 41: 325--328.

28. Frazier WC. A method for the detection of changes in gelatin due to bacteria. I Infect Dis 1926; 39: 302-309.

29. Allen PW. A simple method for the classification of bacteria as to diastase production. $J$ Bacteriol $1918 ; 3$ : 15-17.

30. Holdeman LV, Cato EP, Moore WEC (eds). Chromatographic procedures for analysis of acid and alcohol products. In: Anaerobe laboratory manual. Blacksburg, Virginia, Virginia Polytechnic Institute and State University. 1977: 134-135.

31. Magee JT, Hindmarch MJ, Bennett KW, Duerden BI, Aries RE. A pyrolysis mass spectrometry study of fusobacteria. $J \mathrm{Med}$ Microbiol 1989; 28: 227-236.

32. Read SM, Northcote DH. Minimization of variation in the response to different proteins of the Coomassie blue $G$ dyebinding assay for protein. Anal Biochem 1981; 116: 53-64.

33. Hames BD. One dimensional polyacrylamide gel electrophoresis. In: Hames BD, Rickwood D (eds) Gel electrophoresis of proteins. Oxford, IRL Press. 1990: 1-147.

34. Chen $H$, Cheng $H$, Bjerknes $M$. One-step Coomassie brilliant blue R-250 staining of proteins in polyacrylamide gel. Anal Biochem 1993; 212: 295-296.

35. Berg JN, Scanlon CM. Studies of Fusobacterium necrophorum from bovine hepatic abscesses: biotypes, quantitation, virulence, and antibiotic susceptibility. Am J Vet Res 1982; 43: $1580-1586$

36. Smith GR. Pathogenicity of Fusobacterium necrophorum biovar B. Res Vet Sci 1992; 52: 260-261.

37. Tan ZL, Nagaraja TG, Chengappa MM. Biochemical and biological characterization of ruminal Fusobacterium necrophorum. FEMS Microbiol Lett 1994; 120: 81-86. 